\title{
An Analysis of the Mental Factors of Mobile Foreign Language Learning Based on UTAUT Model
}

\author{
Gan Jingfeng ${ }^{1, a}$ \\ ${ }^{1}$ School of Foreign Language, Southwest Petroleum University, Chengdu, 610500, China \\ ajingfeng.gan@swpu.edu.cn
}

\begin{abstract}
With the popularity of smart phones, mobile foreign language learning will become the future development trend, but at present, whether the mobile foreign language learning is accepted by students or not will become the key factor in the implementation of mobile language learning project. Therefore, the influence factors of the mobile language learning are studied in this paper. On the basis of UTAUT model, the five mental factors of mobile foreign language learning are summed up, and a questionnaire survey is designed, and the data of the survey results are analyzed by using SPSS software. The results show that perception fun, social influence and the expected effort have a significant impact on mobile language learning, while the preset self-learning management has not significant impact on it, and finally the multi group structural equation model is used for analysis. The results show that the phone type, grade, and gender do not have a role in the regulating the influence factors of Undergraduates' mobile foreign language learning.
\end{abstract}

Keywords: UTAUT development model; undergraduates; mobile foreign language learning; factor analysis

\section{INTRODUCTION}

As the integration of the Internet, mobile phone, with its advantages of convenience, quick and efficient, is applied to every corner of life. In view of the popularity of mobile phones, low cost, and the characteristics to obtain conditions to support mobile learning at any time, mobile phone terminal has incomparable superiority compared with other client terminals [1]. Although the mobile phone has unlimited potential, there are still some challenges, such as the small size of mobile phone screen, short battery life and low network connectivity and other defects, resulting in it difficult to popularize mobile language learning; the mobile language learning has drawn widespread concern in the field of education.

The related research on mobile learning in China is relatively late, and there is a certain gap of the research results compared with foreign countries. In the research methods, in China, there lacks quantitative analysis and development; in the research on the application of UTAUT model, since 2003, Venkatesh et al summarized technology acceptance, summed up and compared the main contacted technology acceptance and adoption model, integrated refining the typical model-- UTAUT. Practice has proved that the UTAUT model is a new technology model, which has a high superiority in accepting new technology, and it is less applied into foreign language learning. Hennington et al analysed the acceptance of electronic medical records by using the UTAUT model, which is vital significance for the information management system and community health care; Yuan Wang et al (2012) investigated the main factors whether to accept the mobile Internet technology by using the UTAUT model, and studied the gender impact [2].

To sum up, the UTAUT model has wide and reliable application in the IT field, and UTAUT is of a certain guiding significance of assisting decision makers to introduce a new technique to accept the influence factors of mobile behaviour intention of learning foreign language. Based on predecessors' research, the influence factors of the undergraduates' mobile foreign language learning have been explored, the data are analysed by using SPSS software, the UTAUT model is used as a reference theory model to study the use influence willingness of undergraduates' mobile foreign language learning.

\section{ESTABLISHMENT OF THE UTAUT MODEL}

UTAUT belongs to the traditional information technology acceptance model, and the UTAUT in view 
of mobile foreign language learning technology in part cannot fully reflect the influence factors of mobile learning, but these factors can affect the amount of users. Taking the student users and mobile foreign language learning environment factors into account, this paper draws the key variables of the UTAUT model and adds the two variables of "Perception fun", "selflearning management", so as to better study the influence factors of foreign language learning of Chinese undergraduates [3].

The "use behavior" in the UTAUT model is deleted in this paper, the "behavior intention of mobile foreign language learning" and various factors were analyzed, and at the same time, it is a comprehensive consideration at an early stage of undergraduates' mobile foreign language learning study in China. The model to be tested in this paper is shown in Figure 1:

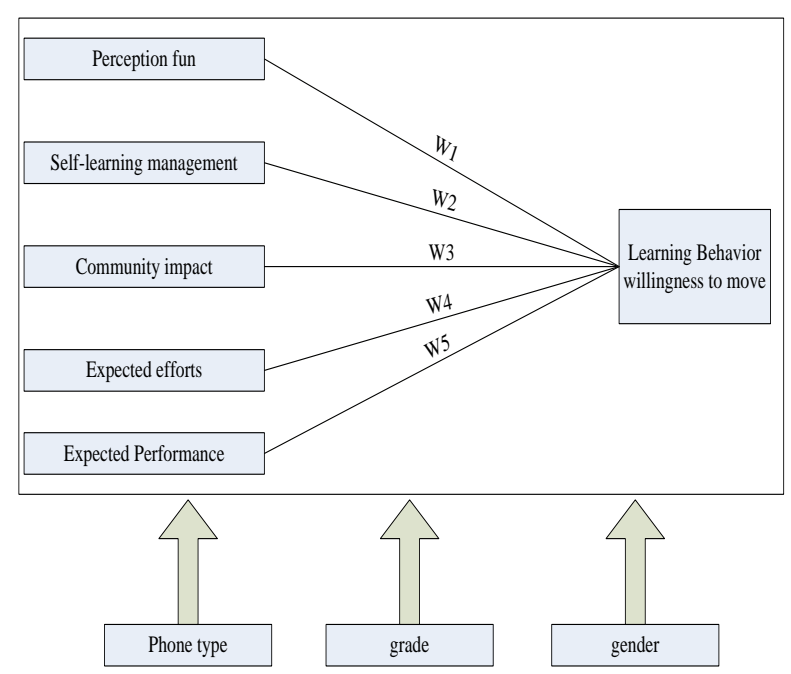

Figure 1 Original model of mobile foreign language learning acceptance

Perception fun, self-management, community impact, expected efforts and expected performance in the model to study hard and expected performance use the decisive factors in mobile foreign language learning. The object of this study is spontaneous, and not compulsory. The model includes control variables: mobile phone type, grade and gender; independent variables: perception fun, self-learning management, social influence, the expected efforts and the expected performance; the dependent variable: the behaviour intention of mobile foreign language learning. It mainly studies the effect of independent variables on the dependent variable through the statistical method and the interference between the control variables [4][5].

\subsection{Measurement dimension and variable definition}

The acceptance model of undergraduates' foreign language learning mainly includes five influence variables: perception fun, self-learning management, community impact, expected efforts and expected performance.

\section{(1) Behaviour intention}

Under certain conditions, the possibilities to learn the foreign language by using their mobile phones in the future expected by users are the behaviour intention for mobile foreign language learning. In this paper, three aspects are respectively set: B11 indicates using mobile phones to learn a foreign language if the conditions allow; B12 indicates willing to use mobile phones regularly to learn a foreign language in the future; B13 indicates to be expected to use mobile phone to learn a foreign language in the future.

\section{(2) Perception fun}

Research shows that the perception fun has a significant impact on the use intention of the Internet. Some people think that perception fun mainly includes 3 aspects: happiness in the interaction process; the initiation of the interaction process and concentration interaction. In the process of using computer systems, people who have a happy experience are more suitable for the use of learning a foreign language. The measurement dimensions of perception fun are respectively as follows: $\mathrm{CP} 1$ indicates the use of mobile phone enhances classroom interaction of foreign language learning; CP2 indicates the use of mobile phone guides the exploration of foreign language learning; CP3 indicates the use of mobile phone stimulate interest in learning foreign language; CP4 indicates the use of mobile phone enhance learning fun to learn a foreign language.

\section{(3) Self-learning management}

Self-learning management mainly refers the selfdiscipline and can fully autonomous participate in learning to a certain degree, it is expected that a person's self-learning management level can have a positive impact on the behaviour intention of mobile foreign language learning. The measurement dimensions of self - learning management of foreign language learning are mainly divided into: SM1 indicates to develop a foreign language learning program on one's own; SM2 indicates effectively manage one's time for foreign language learning; SM3 indicates to have a sense of selfdiscipline in the process of foreign language learning, can skilfully combine learning with fun; SM4 indicates to be an independent person in the study.

\section{(4) Community impact}

Individual use of new technology is mainly from the impact of the community, for the influence factors of community impact of Chinese undergraduates' foreign language learning, this paper sets the three measurement dimensions, namely: SI1 indicates the use mobile phone to learn foreign languages is approved by the teacher; SI2 indicates the impact of friends' use of mobile phone 
to learn foreign languages on me; SI3 indicates the recommendation of classmates' use of mobile phone to learn foreign languages affects my use of mobile phone to learn foreign languages.

\section{(5) Expected efforts}

Expected effort is a key factor in the use of mobile phone for the behaviour intention of foreign language learning, the initial use of mobile phone to learn foreign languages depends mainly on whether the mobile phone system is flexible to be accepted by students. Measurement dimensions of expected effort are respectively as follows: EE1 indicates to easily adapt to the mobile phone to learn a foreign language; EE2 can easily control the mobile phone use to learn a foreign language; EE3 indicates to easily operate mobile phone in the foreign language learning process.

\section{(6) Expected performance}

Expected performance is the best predictors of the behaviour intention to use mobile phone for foreign language learning. Age and gender have a certain effect on the expected performance. In the process of learning a foreign language, mobile foreign language learning can help students quickly and flexibly complete the task of learning. In this paper, four measurement dimensions of expected performance are chosen: PE1 indicates the important information obtained by using mobile phone at any time; PE2 indicates the uses of mobile phone can utilize the fragmented time; PE3 indicates the use of mobile phone can improve the foreign language; PE4 indicates the use of mobile phone can improve the efficiency of learning a foreign language.

\subsection{Research hypothesis}

Research hypothesis is a speculative and hypothetical interpretation, mainly at the initial stage of the study, based on the researcher's understanding of the problem, and combining the predecessors' research experience; it proposed research the temporary solution to the problem studied. According to the characteristics of the current undergraduates' use of mobile phone for foreign language learning, the control variable of mobile phone type is added. A positive impact on Undergraduates' behaviour intention to use mobile phone for foreign language learning is denoted as a; the interference of mobile phone type, gender, grade is denoted as b; perception fun is denoted as $\mathrm{W} 1$; selflearning management is denoted as W2; community impact is denoted as W3; expected efforts are denoted as W4, the expected performance is denoted as W5.

\section{STUDY ON THE MENTAL FACTORS OF CHINESE UNDERGRADUATES' FOREIGN LANGUAGE LEARNING}

This paper collects research data mainly through the questionnaire survey method, and establishes the basic personal information in accordance with the above process, which mainly includes the phone type, grade, gender. And it mainly analyses whether different cell types, different genders and different grades have an impact on undergraduates' behaviour intention of foreign language learning by using the mobile phone. The main body contains five variables that affect the behaviour intention of students' foreign language learning. And the measurement items of the corresponding variables are designed.

The behaviour intention of mobile foreign language learning mainly consists of three aspects of measurement items and is divided into three types in accordance with the current use situation of mobile foreign language learning. according to the analysis of behaviour intention of users' mobile language learning, the community impact is mainly made up of four measurement items, reflecting the effect of different groups of surrounding people on the users' use of mobile phone for foreign language learning [6]. For individuals, SI1 is set to be teachers, SI2 is set to be family members, SI3 is set to be the cognitive situation of students or friends to use mobile phone for learning. Self-learning management mainly refers to the level of SM1 plan development of undergraduates, SM2 refers to the time management, SM3 is self-discipline and SM4 is the composition of autonomy. EE1 measures the adaptability of mobile foreign language learning; EE2 reflects the proficiency of mobile phone foreign language learning; EE3 measures the complexity of mobile foreign language learning. The expected performance is composed of four different measurement items, reflecting the usefulness of mobile foreign language learning. PE1 measures the content provided by mobile foreign language learning; PE2 measures the relative advantages of mobile foreign language learning; PE3 measures the achievement expectation of using mobile phone for mobile learning; PE4 measures efficiency expectations of undergraduates' perception of mobile learning. The perception fun mainly reflects the happy state brought by the undergraduates' mobile learning [7].

Factors analysis is conducted on the questions keeping discrimination, so as to test the construct validity of the scale. The test result of the questionnaire is 0.607 , the Bartlett spherical degree test is 412.332 $(\mathrm{df}=153), \mathrm{p}<0.001$, proving the validity of the structure is good; the projects have the common factor, and which is suitable for the exploratory analysis. Test results are shown in Table 1: 
It can be seen from the above table, after the removal of 3 choices, the questions of the above six factors are basically in agreement. Finally, the reliability of the questionnaire is tested through the Alpha method, and the coefficient of overall $\mathrm{a}$ is obtained to be 0.832 , which shows that the reliability is better, and thus the questionnaire is determined.

Table 1. Exploratory factor analysis table

\begin{tabular}{|c|c|c|c|c|c|c|}
\hline & $\begin{array}{c}\text { Community } \\
\text { impact }\end{array}$ & $\begin{array}{l}\text { Expected } \\
\text { efforts }\end{array}$ & $\begin{array}{c}\text { Perception } \\
\text { fun } \\
\end{array}$ & $\begin{array}{c}\text { Expected } \\
\text { performance } \\
\end{array}$ & $\begin{array}{l}\text { Behavior } \\
\text { intention }\end{array}$ & $\begin{array}{l}\text { Self-learning } \\
\text { management }\end{array}$ \\
\hline SI1 & .625 & & & & & \\
\hline SI2 & .721 & & & & & \\
\hline SI3 & .903 & & & & & \\
\hline EE1 & & .627 & & & & \\
\hline EE2 & & .777 & & & & \\
\hline EE3 & & .887 & & & & \\
\hline CP1 & & & .689 & & & \\
\hline CP2 & & & .797 & & & \\
\hline CP3 & & & .852 & & & \\
\hline PE1 & & & & .847 & & \\
\hline PE2 & & & & .616 & & \\
\hline PE3 & & & & .852 & & \\
\hline Bl1 & & & & & .809 & \\
\hline $\mathrm{BI} 2$ & & & & & .514 & \\
\hline $\mathrm{BI3}$ & & & & & .853 & \\
\hline SM2 & & & & & & .929 \\
\hline SM3 & & & & & & .904 \\
\hline SM4 & & & & & & .852 \\
\hline
\end{tabular}

\section{STATISTICS AND ANALYSIS OF RESEARCH DATA}

\subsection{Reliability and validity analysis}

Reliability refers to the consistency of the results obtained after repeated measurements, the higher the value; the more stable the results of the questionnaire. In this paper, the reliability of the data is measured by Cronbach a, which is taken as the reliability index of the data coefficient, as shown in Table 2:

Table 2. Coefficient evaluation criteria of Cronbach a

\begin{tabular}{|c|c|}
\hline Cronbach a & Standard \\
\hline $0.60-0.65$ & Unacceptable \\
\hline $0.65-0.70$ & Minimum acceptable \\
\hline $0.70-0.80$ & Quite good \\
\hline $0.80-0.90$ & Very nice \\
\hline
\end{tabular}

SPSS software is used to test the reliability of the questionnaire results, the results show that: the entire item - subscales are more than 0.75 ; the coefficient of the overall a scale is 0.839 , which shows that the questionnaire reliability is better.

\subsection{Validity analysis}

It is not difficult to see from Table 4 that the validity test of the questionnaire showed that the fitting number exceeds the reasonable range of 1-3, the adaptation degree of the model cannot the realize the best effect. And the models of 1-5 are allowed; the smaller of CFI, MFI, FNI, TKI, the worse of the model adaptation degree, the closer the number is to 1 , the better the model is.

\subsection{Model development}

Revise the hypothetical original model so as to make the fitting index of the model reach the standard.

Model1: On the basis of the original model, after the removal of the self-learning management, the behaviour intention of mobile foreign language learning is taken as dependent variable and perception fun, community impact, expected efforts and expected performance are taken as exogenous variables. 
Model 2: The behaviour intention of mobile foreign language learning is taken as dependent variable and self-learning management, community impact, expected efforts and expected performance are taken as the external variables.

Table 3. Reliability of item - subscale

\begin{tabular}{|c|c|c|}
\hline Variable & Number of Problem & Criteria of Cronbach a \\
\hline Expected performance & 3 & .769 \\
\hline Expected efforts & 3 & .813 \\
\hline Community impact & 3 & .771 \\
\hline Self-learning management & 3 & .743 \\
\hline Perception fun & 3 & .866 \\
\hline Behavior intention & 3 & .777 \\
\hline Entirety & 18 & .839 \\
\hline
\end{tabular}

Table 4. Overall fitting degree of the initial model

\begin{tabular}{|c|c|c|}
\hline $\begin{array}{c}\text { Statistical test } \\
\text { quantity }\end{array}$ & Fitting values of the model & Adaptation criteria or the critical value \\
\hline RMSEA value & .007 & $<.05$ (Good-adaptation) $<.80$ (Reasonable-adaptation) \\
\hline CFI value & .866 & $>.90$ \\
\hline TLI value & .824 & $>.90$ \\
\hline IFI value & .868 & $>.90$ \\
\hline NFI value & .829 & $>.90$ \\
\hline X/df & 3.776 & $1 \sim 3$ better fitting degree of the model \\
\hline
\end{tabular}

Table 5. Overall fitting degree comparison of each model

\begin{tabular}{|c|c|c|c|c|c|c|}
\hline & RMSEA & CFI & TLI & IFI & NFI & x/df \\
\hline $\begin{array}{c}\text { Original } \\
\text { model }\end{array}$ & .077 & .916 & .824 & .868 & .829 & 3.776 \\
\hline Model 1 & .092 & .866 & .801 & .859 & .830 & 5.000 \\
\hline Model 2 & .051 & .857 & .922 & .943 & .901 & 2.234 \\
\hline Model 3 & .060 & .942 & & .943 & .912 & 2.685 \\
\hline
\end{tabular}

Model 3: On the basis of Model 2, the self-learning management is removed, and the behavior intention of mobile foreign language learning is taken as dependent variable and community impact, expected efforts and expected performance are taken as the external variables.

The above three revised models are tested by AMOS, and the results are shown in Table 5:

It can be known that the fitting indexes of Model 2 and Model 3 are between 2 and 3, so two models are ideal and the approximation error is less than 0.08, the relative fitting index is greater than 0.9 , proving Model 2 and Model 3 are reasonable. In the case of a comprehensively considering the five factors, the influence factors of undergraduates' mobile foreign language learning are identified, as shown in the following figure:

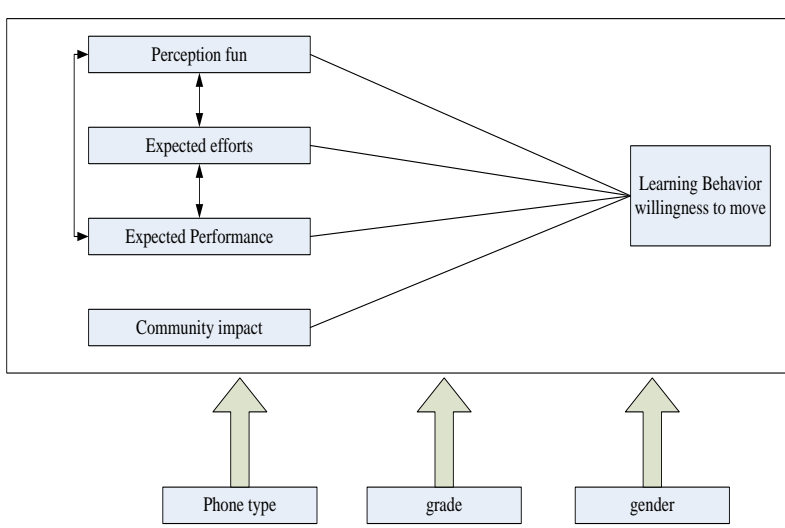

Figure 2 Selection of research model

\section{ANALYSIS OF RESULTS TESTED BY HYPOTHESIS}

The results of the final overall path are shown in the following table. The parameters in Table 6 are the 
standard parameters, which indicate that the test results

hypothesis. of $\mathrm{W} 1$ to $\mathrm{W} 5$ are corresponding to the corresponding

Table 6. Regression coefficient of path standard and the corresponding results tested by hypothesis

\begin{tabular}{|c|c|c|c|c|}
\hline Path specification & Pass or not & $\begin{array}{c}\text { Correspondence } \\
\text { hypothesis }\end{array}$ & P value & $\begin{array}{c}\text { Coefficient of } \\
\text { path }\end{array}$ \\
\hline $\begin{array}{c}\text { Perception fun to } \\
\text { Behavior intention }\end{array}$ & Yes & W5a & $\mathrm{p}<0.01$ & 0.370 \\
\hline $\begin{array}{c}\text { Community impact to } \\
\text { Behavior intention }\end{array}$ & Yes & W3a & $\mathrm{p}<0.01$ & 0.284 \\
\hline $\begin{array}{c}\text { Expected efforts to } \\
\text { Behavior intention }\end{array}$ & Yes & W2a & $\mathrm{p}<0.05$ & 0.125 \\
\hline $\begin{array}{c}\text { Expected performance to } \\
\text { Behavior intention }\end{array}$ & Yes & W1a & $\mathrm{p}<0.01$ & 0.348 \\
\hline
\end{tabular}

It can be seen from the above table that W1a, W2a, W3a and W5a all pass the hypothesis, and standardized coefficients are between 0.12 and 0.5 . The results show that community impact, perception fun, expected efforts, as well as the expected performance have a significant impact on the intention. W4a didn't pass the test, indicating the self-learning management has no significant impact on the intention. The pairwise correlation coefficients of perception fun, expected effort and expected performance are shown in Table 7:

Table 7. Correlation coefficients

\begin{tabular}{|c|c|c|}
\hline $\begin{array}{c}\text { Related } \\
\text { relationship }\end{array}$ & P value & $\begin{array}{c}\text { Correlation } \\
\text { estimate }\end{array}$ \\
\hline $\begin{array}{c}\text { Perception fun } \\
\text { and Expected } \\
\text { performance }\end{array}$ & $\mathrm{p}<0.01$ & 0.570 \\
\hline $\begin{array}{c}\text { Expected } \\
\text { efforts and } \\
\text { Perception fun }\end{array}$ & $\mathrm{p}<0.01$ & 0.470 \\
\hline $\begin{array}{c}\text { Expected } \\
\text { performance } \\
\text { and Expected } \\
\text { efforts }\end{array}$ & $\mathrm{p}<0.01$ & 0.545 \\
\hline
\end{tabular}

Whether mobile phone type, grade and gender and other factor have interference effect hypothesis on foreign dependent variable on the external dependent variables, a group structure models are used for analysis. The judgment standard is the absolute value of critical ratio of the path coefficients differences between groups in pairs greater than 1.96. If it is less than 1.96, it is assumed that the two are equal by weight, namely, invariance between groups. Otherwise, it is considered that the path coefficient is different. In order to verify the hypothesis, two groups of boys and girls were randomly selected to compare, and the results are shown in Table 8:

It is shown in the above table that all of the hypotheses pass the test, which proved that gender, perception fun, community impact, expected efforts and expected performance had no interference effect on the behaviour intention of moving foreign language learning.

Table 8. Critical ratio of path parameter differences between gender groups and results tested by hypothesis

\begin{tabular}{|c|c|c|c|}
\hline Path specification & Pass or not & $\begin{array}{c}\text { Correspondence } \\
\text { hypothesis }\end{array}$ & Gender \\
\hline $\begin{array}{c}\text { Community impact to Behavior } \\
\text { intention }\end{array}$ & No & W3b1 & 0.576 \\
\hline Perception fun to Behavior intention & No & W5b1 & -1.872 \\
\hline Expected efforts to Behavior intention & No & W2b1 & 0.946 \\
\hline $\begin{array}{c}\text { Expected performance to Behavior } \\
\text { intention }\end{array}$ & No & W1b1 & -0.240 \\
\hline
\end{tabular}

Table 9. Critical ratio of path parameter differences between age groups and results tested by hypothesis

\begin{tabular}{|c|c|c|c|}
\hline Path specification & Pass or not & $\begin{array}{c}\text { Correspondence } \\
\text { hypothesis }\end{array}$ & Age \\
\hline Community impact to Behavior intention & No & W3b2 & 1.375 \\
\hline Perception fun to Behavior intention & No & W5b2 & -0.539 \\
\hline Expected efforts to Behavior intention & No & W2b2 & -1.270 \\
\hline
\end{tabular}




\begin{tabular}{|c|c|c|c|}
\hline $\begin{array}{c}\text { Expected performance to Behavior } \\
\text { intention }\end{array}$ & No & W1b2 & 0.695 \\
\hline
\end{tabular}

Table 10. Critical ratio of path parameter differences between experience groups and results tested by hypothesis

\begin{tabular}{|c|c|c|c|}
\hline Path specification & $\begin{array}{c}\text { Pass or } \\
\text { not }\end{array}$ & $\begin{array}{c}\text { Corresponden } \\
\text { ce hypothesis }\end{array}$ & Type of phone \\
\hline Community impact to Behavior intention & No & W3b3 & 0.466 \\
\hline Perception fun to Behavior intention & No & W5b3 & 0.928 \\
\hline Expected efforts to Behavior intention & No & W2b3 & -1.456 \\
\hline $\begin{array}{c}\text { Expected performance to Behavior } \\
\text { intention }\end{array}$ & No & W1b3 & 0.121 \\
\hline
\end{tabular}

In accordance with the above hypothesis model and parameter estimation and analysis results of multi group result model, the path of the model obtained is shown in Figure 3:

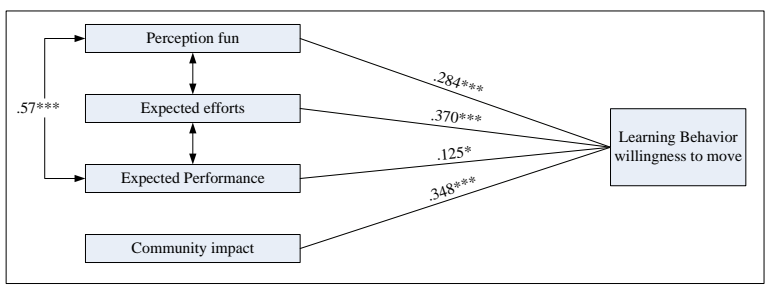

Figure 3 Path coefficient diagram

It is not difficult to see from the above diagram that community impact, perception fun, expected efforts and expected performance all affect the willingness of mobile foreign language learning, and self- learning management have no limitations on it. In accordance with the order of the four factors of influence degree from weak to strong, it can be obtained that expected efforts < community impact< expected performance < perception fun, in which, the condition variables are: the impact of mobile phones, grade and gender on the interference of various factors is not significant.

Through the above analysis, the results show that the W1a, W2a, W3a and W5a in the hypothesis were validated by the data, and the corresponding other results did not pass the validation.

\section{CONCLUSIONS}

Based on referring to the UTAUT model, and after the addition of the two factors of "self- learning management" and "perception fun", the UTAUT development model is constructed to explore the influence factors of behavior intention of undergraduates' mobile foreign language learning in China. The results show that the community impact, expected efforts and expected performance have significant impact on the behavior intention of mobile foreign language learning. The results of data analysis show that the factor of "self-learning management" has no significant effect on the intention behavior of mobile foreign language learning. However, "perception fun" has a significant effect on the behavior intention. This study not only verifies the UTAUT model but also expands the applicability of the UTAUT model in Chinese undergraduates' foreign language learning field.

\section{ACKNOWLEDGMENT}

This work is supported by the Project of Sichuan Applied Psychology Research Centre. (Project Number: CSXL-162215).

\section{REFERENCES}

[1] A. A. Ayele, D.V. Sreenivasarao. Artificial neural network analysis of academic performance of students in virtual learning environments[J], International Journal of Innovative Research in Computer \& Communication Engineering, 1, 2013.

[2] Yuan Wang. The role of textbook learning resources in e-learning: A taxonomic study. Journal of the Association for Information Science \& Technology, 65, 2012.

[3] Juan Zheng, Wanli Xing. Profiling self-regulation behaviors in STEM learning of engineering design[J], Computers \& Education, 2019.

[4] S.V. Laer, J. Elen. The effect of cues for calibration on learners' self-regulated learning through changes in learners' learning behavior and outcomes[J], Computers \& Education, 2019.

[5] A.H. Aijaz, HU Wajid, Supporting learners' selfregulated learning in Massive Open Online Courses[J], Universal Access in the Information Society. 2018.

[6] A. J. Flanagin, M. Metzger. Quantitative structureactivity relationship analysis using deep learning based on a novel molecular image input technique[J], Bioorganic \& Medicinal Chemistry Letters, 2018.

[7] D. Bhatti, J. Bertoni. Feasibility of online medical education for distance learning: Experiences of mini-fellowship in movement disorders[J], Journal of the Neurological Sciences, 2019. 